\title{
Processing of Leather Using Deep Eutectic Solvents
}

\author{
Andrew P. Abbott, $*^{\mathrm{a}}$ Omaymah Alaysuy, ${ }^{\mathrm{a}}$ A. Paula M. Antunes, ${ }^{\mathrm{b}}$ Andrew C. Douglas, ${ }^{\mathrm{a}}$ Jeffry \\ Guthrie-Strachan, ${ }^{\text {b,c }}$ William R. Wise ${ }^{\mathrm{b}}$ \\ ${ }^{a}$ Chemistry Department, University of Leicester, Leicester, LE1 7RH, UK \\ ${ }^{\mathrm{b}}$ Institute for Creative Leather Technologies, University of Northampton, Northampton, \\ NN2 7AL, UK \\ ${ }^{\mathrm{c}}$ Trumpler GmbH \& Co. KG, Worms, 67547, Germany
}

\begin{abstract}
Processing of leather has an historical reputation as a chemically and energetically intensive process which produces large volumes of aqueous waste. Saline pollution combined with heavy-metal, dyes and acid and base streams make leather production an ecologically sensitive industry. The current study shows that a variety of deep eutectic solvents, DESs may be used for the tanning, fatliquoring and dyeing of animal hides, being particularly useful for mineral (chromium) and vegetable tanning processes. The tanning agents are able to penetrate rapidly into the hide, driven by lyotropic swelling due to their high ionic strength. The samples are shown to have similar tanning agent content to the currently used aqueous chromium (III) sulfate solution, however the waste metal content is shown to be significantly reduced. Incorporation of the DES Ethaline into the leather significantly alters the swelling properties of the leather increasing the flexibility and ductility of the material, therefore acting in the same manner as a fatliquor which lubricates or plasticises the fibrous structure of the collagen. Ethaline was also used to transport a lysochromic dye throughout the cross-section of the leather, and the hydrophobicity of the dye prevents leaching into the aqueous wash solution. Physical measurements show that leather processed using DESs have similar mechanical properties to that processed using conventional aqueous systems.
\end{abstract}

\section{Keywords}

Seep eutectic solvent, leather, collagen, tanning, fatliquoring, dyeing. 


\section{Introduction}

The production of leather is an industry that dates back over 6000 years and elements of the process have changed relatively little in the past 100 years. Around 6.5 million tonnes of wet salted hides are processed annually using an estimated 3.5 million tonnes of chemicals. ${ }^{1}$ Leather processing typically involves a number of processing steps. Initially the hide or skin is preserved with salt until required. A number of processes are thus initiated and these are the soaking of the hide or skin to remove the salt as well to rehydrate the material to return to or near its original state. This is followed with the removal of the hair from the hide using a reducing agent in a high $\mathrm{pH}$ solution containing calcium hydroxide (liming). This process is subsequently followed by a reduction in $\mathrm{pH}$ ('deliming') to reduce swelling and prepare the hide for enzymatic treatment or bating (a crude mixture of proteolytic enzymes) to remove non-structural proteins. The hide is further subjected to acid treatment (pickling), followed by the tanning process using a metal salt or vegetable tannins. This is followed by dyeing, retanning and fatliquoring processes before finishing the leather with the application of a surface coating. ${ }^{2}$ Each batch of hides requires days of soaking or stirring in a series of concentrated aqueous solutions. It is estimated that over $600 \mathrm{~kg}$ of waste is generated and 30$35 \mathrm{~m}^{3}$ of water is used for every tonne of wet-salted hide which results in 200-300 kg of leather. ${ }^{3}$ The leather manufacturing process is well known for the amount of aqueous waste produced. ${ }^{4,5}$ To date most approaches to improve the green metrics of leather production have been either end-of-pipe solutions to neutralise waste or mechanical improvements to decrease the volume of tanning solution required. Numerous green alternatives have been proposed including biological and electrochemical waste water treatment steps. ${ }^{6,7}$

One of the biggest concerns is the emission of heavy metals into the environment particularly chromium. Approximately $80-85 \%$ of the total leathers produced industrially are processed using a chromium-based tanning process, principally as it allows the leather to be manipulated at high temperatures without visible shrinkage. The chrome tanning reaction occurs between partially hydrolysed chromium (III) sulfate species and ionised carboxyl groups on the collagen molecule forming covalent complexes usually in the $\mathrm{pH}$ range from $2.5-4.5$, due to the solubility of the $\mathrm{Cr}$ (III) complex. This tanning reaction is influenced by $\mathrm{pH}$, temperature and the presence of counter ions in solution. A great deal of research has gone into replacing chromium, but no commercially viable process has yet met the demands of the industry in terms of cost-efficiency. Basic chromium (III) sulfate is extensively used as the tanning agent. Typical tanning solutions contain approximately 1.5 to $2 \% \mathrm{Cr}_{2} \mathrm{O}_{3}$ by 
weight and after tanning the solution may contain up to $30 \%$ of its original chromium content. This equates to $4-6 \mathrm{~g}$ of $\mathrm{Cr}_{2} \mathrm{O}_{3}$ per $\mathrm{kg}$ of hide. The chromium is usually precipitated and recovered from solution using alkalis, and while in developed countries recovery is extremely efficient, some countries experience significant environmental pollution due primarily to the cost of remediation. ${ }^{8}$

The majority of waste-water produced in the manufacture of leather originates from the pretanning stages such as salting, washing, liming, deliming processes etc. However there is still a significant amount waste-water produced from the post-tanning stages such as re-tanning, fatliquoring and dyeing. ${ }^{3}$ The dyeing process typically requires $2000-3000 \mathrm{~kg}$ of water to solubilise $5 \mathrm{~kg}$ of dye for every $1000 \mathrm{~kg}$ of leather. In developed regions the waste water is disposed of once the processes have been completed using appropriate effluent treatment systems; however in developing countries, especially in small independent tanneries, any water effluent is unlikely to be treated before being released into the local water systems due to prohibitive costs.

In the current approach transformative tanning, fatliquoring and dyeing stages for leather manufacture are proposed using a novel type of solvent. Deep Eutectic Solvents (DESs), are mixtures of quaternary ammonium halides with either metal salts or hydrogen bond donors. ${ }^{9}$ ${ }^{10}$ Research studies undertaken by Abbott et al. have recently shown that eutectic mixtures of metal salts with amides, such as urea, also form useful liquids. ${ }^{11,12}$ They have properties that are comparable with ionic liquids and have been used for a wide variety of applications including metal processing, synthesis and control of phase transfer. ${ }^{9}$ For the application to leather processing the DESs demonstrate the advantage of high solubility for polar compounds, such as vegetable tanning agents. They can be formulated to contain metals such as chromium but also dissolve non-polar compounds such as dyes. Previously, eutectic mixtures of 1 choline chloride: $2 \mathrm{CrCl}_{3} \cdot 6 \mathrm{H}_{2} \mathrm{O}^{13}$ and 2 urea: $1 \mathrm{CrCl}_{3} \cdot 6 \mathrm{H}_{2} \mathrm{O}^{12}$ have been used for the electrodeposition of chromium, circumventing the use of chromic acid. This is an effective way of making an extremely concentrated active ingredient. The 1 choline chloride: $2 \mathrm{CrCl}_{3} \cdot 6 \mathrm{H}_{2} \mathrm{O}$ for example has $4.75 \mathrm{~mol} \mathrm{dm}^{-3}$ chromium salt. In water a large excess of ancillary is used to allow the chromium to partition into the hide, using the DES solvent system, the aim is to ensure that all the active ingredients enter the hide and are fixed. Ionic liquids have not been applied to leather tanning before although they have been used to remove inter-fibrillary materials in the pre-tanning step $^{14}$ and dilute aqueous solutions of choline thioglycolate have been used for hair removal. ${ }^{15}$ 
DESs tend to be relatively viscous and their properties can be judiciously varied through the choice of components. The ingress of species into leather is dominated by interfacial processes and the current aqueous tanning solutions operate under relatively concentrated conditions to ensure that the species partition into the solid, largely ionic matrix. In this study it is aimed to show that the use of DESs with chromium- and vegetable-tanning agents can decrease the loss of active ingredients. It will also be shown that dye emissions can be significantly reduced using DESs, and entrapment of the ionic component into the leather can act as an in-built plasticiser.

\section{Experimental}

The synthesis of the DESs was carried out using the method described in the literature..$^{10,11,12,13}$ The applicability of three different types of DES solvents to tan hides was tested:

1 Choline chloride: $2 \mathrm{CrCl}_{3} \cdot 6 \mathrm{H}_{2} \mathrm{O}$

2 Urea: $1 \mathrm{CrCl}_{3} \cdot 6 \mathrm{H}_{2} \mathrm{O}$

2 Urea: $1 \mathrm{KCr}\left(\mathrm{SO}_{4}\right)_{2} \cdot 10 \mathrm{H}_{2} \mathrm{O}$

For each case the components (All Aldrich < 99\%) were used as received. The two components were mixed in the relevant ratios using magnetic stirring at $50^{\circ} \mathrm{C}$. The components were mixed until no more solid crystals remained which usually took between 2$3 \mathrm{hrs}$ depending on the volume.

Ethaline 200 was used for the vegetable tanning, dyeing and fat liquoring experiments. It is a eutectic mixture of 2 mol. eq. ethylene glycol and 1 mol. eq. choline chloride, $\mathrm{ChCl}$. It was made in the same way as the three chromium containing eutectic mixtures. Mimosa (Forestal Mimosa Ltd., South Africa) and Chestnut (Silvateam, Italy) vegetable tanning agents were used as received. Samples of bovine hide were pre-treated and pickled according to a conventional leather manufacturing process. The final $\mathrm{pH}$ of the pickled hide was approximately 4 . The bulk water was removed from the hide using a sammying machine and the final water content of the hide prior to tanning with DESs was determined gravimetrically to be $62 \mathrm{wt} \%$. Bovine hide samples $\left(100 \mathrm{~cm}^{2}\right)$ weighing $50 \pm 2 \mathrm{~g}$ were tanned by contacting them with $23 \pm 2 \mathrm{~g}$ of DES for 18 hours at room temperature without mechanical action. Following tanning, the excess DES was skimmed from the surface using a metal blade and the hide reweighed. The sample was then washed in cold water or 1 mol dm${ }^{-3}$ sodium sulphate solution and allowed to air dry before being analysed by the techniques listed below. Negligible leaching of the DES from the hide into the water was observed during the washing 
stage. The $\mathrm{Cr}(\mathrm{III})$ reference sample was tanned according to a conventional aqueous recipe. Following the tanning trials the chromium content was determined, following the total digestion of the tanned leather samples, using an inductive coupled plasma-optical emission spectrometer (ICP-OES) according to the standard method BS EN ISO 5398-4:2007. The vegetable tanning was carried out in the same way as the chromium tanning using a eutectic mixture of Ethaline 200 at a loading of $10 \mathrm{wt} \%$ of either ground mimosa bark or ground chestnut wood bark.

For the dyeing experiments: $0.4 \mathrm{~g}$ of Sudan Black B was mixed with $200 \mathrm{ml}$ of Ethaline 200 to make a $4.38 \times 10^{-3} \mathrm{~mol} \mathrm{dm}^{-3}$ dye solution. Samples of dried wet-blue leather $\left(5 \mathrm{~cm}^{2}\right)$ were fully submerged in the Ethaline 200 and Sudan Black B solution. The samples were then left in the solution at $70{ }^{\circ} \mathrm{C}$ for $24 \mathrm{hrs}$. Once completed, the samples were washed for $15 \mathrm{~min}$ in deionised water, placed on absorbent paper and air-dried for a minimum of $24 \mathrm{hrs}$ at room temperature. Fat liquoring experiments were carried out using conventionally chrome tanned leather (which had been air dried prior to use). Samples $(10 \times 10 \mathrm{~cm})$ were immersed in Ethaline 200 at the specified temperature for the defined length of time. Following this the samples were washed for $15 \mathrm{~min}$ in deionised water, placed on absorbent paper and air-dried for a minimum of $24 \mathrm{hrs}$ at room temperature. The mass before and after treatment were determined using a 4 figure scientific balance.

The shrinkage temperature (Ts) was determined using differential scanning calorimetry (DSC) with $40 \mu \mathrm{L}$ gold-lined high pressure pans with a heating rate of $5{ }^{\circ} \mathrm{C} \mathrm{min}^{-1}$ from 20 to $140{ }^{\circ} \mathrm{C}$. The measurement of the shrinkage temperature is important to determine the efficacy of a tanning agent to stabilise the collagen fibres and usually measured in a 'wet state'. Samples were conditioned to $20{ }^{\circ} \mathrm{C}$ and $65 \%$ relative humidity according to BS EN ISO 3376:2011 and the tensile strength and elongation at break were determined using an Instron tensiometer according to BS EN ISO 3376:2011. Samples were analysed using a Zeta 3D Microscope. A 5x objective magnification with reflective light was used.

\section{Results}

\section{Chromium Tanning:}

The ability to create highly concentrated $\mathrm{Cr}$ (III)-based liquids offers the potential to formulate a liquid-active ingredient. The aim is to liquefy the tanning agent through complexation to avoid the use of a solvent and thus minimise the total amount of material used. Any excess chromium salt can be mechanically removed and reused as it does not change the overall chemical composition since the leather absorbs both the anionic and 
cationic component of the liquid. The majority of the costs with the tanning process are associated with the chromium salt and the recovery from dilute aqueous solutions after processing. Using DESs removes the solvent from the process and increases the efficiency of chromium salt uptake into the hide while minimising the treatment of aqueous effluent. To demonstrate the uptake of chromium into the hide, the shrinkage temperature and chrome content was determined for samples of bovine hide treated with the three DESs listed above.

Table 1 shows the chromium content and shrinkage temperatures of the hide obtained from conventional $\mathrm{Cr}$ (III) tanning process using aqueous chromium(III) sulfate (33\% basified, 25 wt $\% \mathrm{Cr}_{2} \mathrm{O}_{3}$ ) with the three chromium-based DESs. It can be seen that all three DESs yield samples with a chromium content that is comparable with aqueous chromium tanning. The urea eutectics produce higher chromium content than the choline chloride based eutectics which is thought to be due to the charge on the chromium species. Both urea eutectics produce cationic chromium species whereas the choline chloride species is predominantly anionic. $^{12}$ The hide samples increased in mass between 9 and 19\%. Given that the chromium content of the 3 liquids is between 9 and 18\% this corresponds approximately to the $\mathrm{Cr}$ content listed in Table 1. The data shows that both components of the DESs are absorbed into the collagen structure. The water absorbed by the recovered DES can easily be evaporated off to return it to its original composition. This is a practice which is already employed in the chromium electroplating process using the same liquid. ${ }^{16}$

It has previously been shown that considerably different chromium speciation is obtained in the $1 \mathrm{ChCl}: 2 \mathrm{CrCl}_{3} \cdot 6 \mathrm{H}_{2} \mathrm{O}$ and 2 urea: $1 \mathrm{CrCl}_{3} \cdot 6 \mathrm{H}_{2} \mathrm{O}$ eutectics. ${ }^{12}$ In the former the chromium species is a mixture of neutral $\mathrm{CrCl}_{3} \cdot 3 \mathrm{H}_{2} \mathrm{O}$ and anionic $\left[\mathrm{CrCl}_{4} \cdot 2 \mathrm{H}_{2} \mathrm{O}\right]^{-}$while in the latter cationic $\left[\mathrm{CrCl}_{2}(\mathrm{OD})_{4}\right]^{+}$predominates (where OD represents an oxygen donator which could be water or urea). The aqueous pre-treated bovine hide was washed in acidic buffer solution to give a $\mathrm{pH}=4$, at which the carbonyl groups on collagen should be largely anionic and this may help cationic chromium complexes bind. At the same time the amine groups should be largely protonated enabling the anionic chromium complexes to bind. ${ }^{2}$

Despite the differences in speciation, the shrinkage temperatures for DES-treated samples are similar. The indicative shrinkage temperatures for hide tanned using DESs are however lower than conventional chrome tanning, although it should be noted that sulfate also plays a significant role in increasing the shrinkage temperature. ${ }^{2}$ The various chromium species diffuse rapidly into the hide samples but chemical binding may be slower than in aqueous solutions potentially due to the higher ionic strength of DESs. It should however be noted that no attempt has been made to optimise the process and fix the chromium in the DES-treated 
samples, whereas this is a requirement of the aqueous process. Fixing is generally achieved by raising the $\mathrm{pH}$, increasing the temperature and/or with the addition of complexing agents. Washing the sample treated with $1 \mathrm{ChCl}: 2 \mathrm{CrCl}_{3} \cdot 6 \mathrm{H}_{2} \mathrm{O}$ with $1 \mathrm{~mol} \mathrm{dm}{ }^{-3}$ sodium sulphate solution increased the shrinkage temperature from 71 to $86{ }^{\circ} \mathrm{C}$ at $\mathrm{pH} 4$ and this increased to $96{ }^{\circ} \mathrm{C}$ when the $\mathrm{pH}$ was increased to 8 . This shows that the chromium can be fixed to the collagen structure irrespective of the anion in the DES solvent. In addition the shrinkage temperatures are comparable to those obtained using conventional chromium tanning solutions. Leather does not tend to experience temperatures close to $100{ }^{\circ} \mathrm{C}$ during its manufacture but the standard specification for "wet blue" stipulates that $\mathrm{T}_{\mathrm{s}}>100{ }^{\circ} \mathrm{C}$ to impart a safety barrier to damaging the leather during subsequent processing. For non-chromium tanned leathers shrinkage temperatures are typically in the range $70-90{ }^{\circ} \mathrm{C} .{ }^{17}$

\begin{tabular}{|l|c|c|c|c|c|}
\hline Tanning agent & $\begin{array}{c}\text { Leather } \mathrm{Cr} \\
\text { content } \\
/ \%\end{array}$ & $\begin{array}{c}\mathrm{T}_{\mathrm{S}} \\
/{ }^{\circ} \mathrm{C}\end{array}$ & $\begin{array}{c}\text { Thickness } \\
/ \mathrm{mm}\end{array}$ & $\begin{array}{c}\text { Tensile } \\
\text { strength } \\
/ \mathrm{MPa}\end{array}$ & $\begin{array}{c}\text { Elongation } \\
/ \%\end{array}$ \\
\hline $\begin{array}{l}\text { Conventional aq. 33\% basic } \\
\mathrm{Cr}(\mathrm{III}) \text { tanning salts }\end{array}$ & 3.04 & 109 & 3.02 & 32.6 & 50.8 \\
\hline $1 \mathrm{ChCl}: 2 \mathrm{CrCl}_{3} \cdot 6 \mathrm{H}_{2} \mathrm{O}$ & 2.27 & 71 & 2.55 & 37.7 & 39.3 \\
\hline 2 Urea: $1 \mathrm{CrCl}_{3} \cdot 6 \mathrm{H}_{2} \mathrm{O}$ & 3.43 & 80 & 2.84 & 27.4 & 34.9 \\
\hline 2 Urea: $1 \mathrm{KCr}_{\left(\mathrm{SO}_{4}\right)_{2} \cdot 10 \mathrm{H}_{2} \mathrm{O}}$ & 3.52 & 83 & 3.10 & 30.3 & 42.5 \\
\hline Mimosa extract & - & 83 & 2.92 & 56.6 & 50.5 \\
\hline Chestnut extract & - & 78 & 2.62 & 43.2 & 65.7 \\
\hline
\end{tabular}

Table 1: Chromium content, shrinkage temperature and mechanical properties of a bovine hide tanned with a conventional process as well as DESs.

Table 1 also shows the strength and elongation of the tanned samples. The samples exhibited similar mechanical strength and elongation at break as the conventional aqueous $\mathrm{Cr}(\mathrm{III})$ tanned leather, showing that the DES solvents have not exhibited deleterious effects on the mechanical properties of the hide. Leather is a highly isotropic material depending which is sensitive to the part of the skin it was taken from, the $\mathrm{pH}$ and the conditions of the aqueous pre-treatment. The value is Table 1 are, however within the variability that could be expected from replicate samples. 

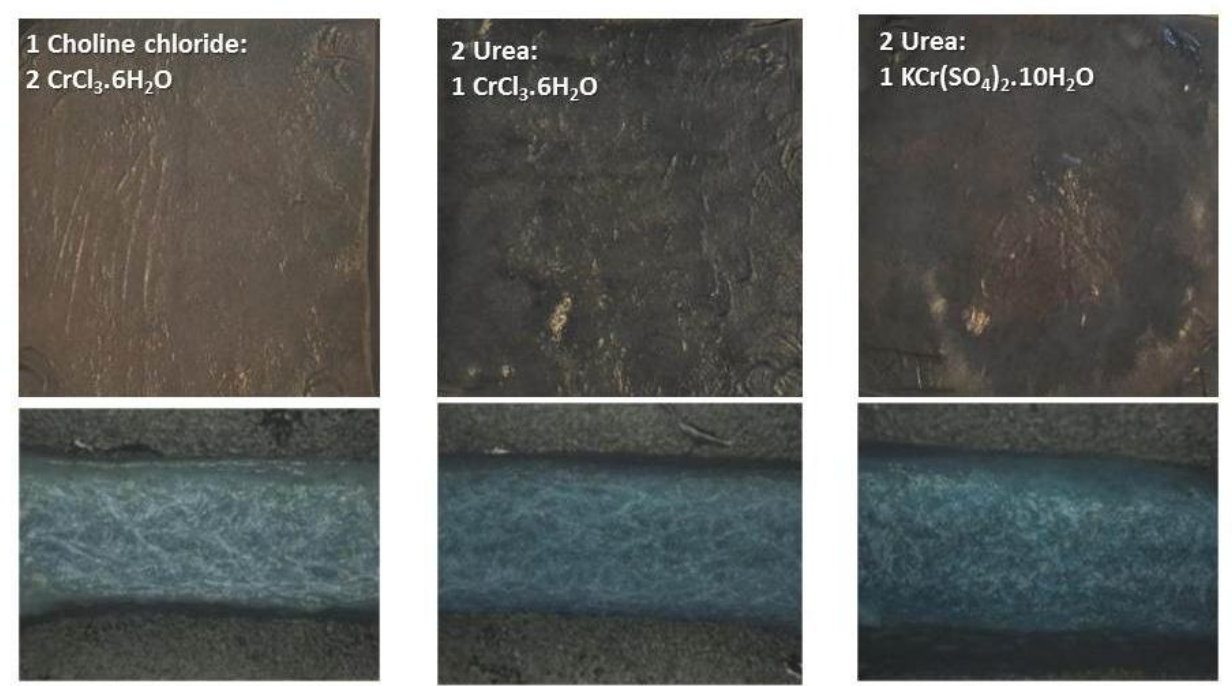

Figure 1: Above: From l to $\mathrm{r}: 10 \times 10 \mathrm{~cm}$ samples of bovine hide, $\mathrm{pH} 4$, tanned in $1 \mathrm{ChCl} 2$ $\mathrm{CrCl}_{3} \cdot 6 \mathrm{H}_{2} \mathrm{O}$; 2 urea: $1 \mathrm{CrCl}_{3} \cdot 6 \mathrm{H}_{2} \mathrm{O}$; and 2 urea: $1 \mathrm{KCr}\left(\mathrm{SO}_{4}\right)_{2} \cdot 10 \mathrm{H}_{2} \mathrm{O}$ for 18 hours. Below: Corresponding cross sections.

Figure 1 shows the optical photographs and cross-sections of the Cr-DES samples listed in Table 1. It can be seen that all samples are intensely coloured by the tanning process. The cross-sectional images show that the tanning agent has penetrated through the material. It is also useful to note that the fibrous structure is retained (c.f. Figure 4 for conventional chromium cross linked structure) and this shows that the DESs do not denature the collagen. Cross-sections taken during the tanning process showed that the urea-based liquids had permeated the hide rapidly suggesting that the treatment period utilised could be considerably optimised with the potential to be more rapid than the aqueous tanning methods. The three DESs are different shades of green resulting from the differences in chromium speciation ${ }^{12}$ and this results in slightly different shades of tanned leather suggesting some differences in the chromium species bound to the collagen.

Chromium salts are used for approximately $80-85 \%$ of tanned leather. ${ }^{18}$ From a "Green" perspective, the concern with chromium tanning of leather relates to the emission of large volumes of dilute aqueous chromium which has to be treated. The tanned leather will retain a variable amount of moisture which is integral to the stability of the collagen structure, making the calculation of Green-metrics quite complex since an exact mass balance is difficult to quantify. The conventional aqueous tanning process starts with an equal mass of aqueous $\mathrm{Cr}$ (III) salt solution so nominally the Sheldon E factor is $>1$ since the hides are subsequently treated with an aqueous base to fix the chromium to the collagen. The water, 
which is the major component by mass, is recycled and the remaining chromium content is usually recovered through a series of precipitation, adsorption or ion exchange processes. ${ }^{19,20,21}$ Notwithstanding, the wastewater may contain between 500 and 3000 ppm chromium. ${ }^{22}$ Recovery of the chromium could bring the $\mathrm{E}$ factor down in the region of 0.002 to 0.005 for this stage.

In principle, although by no means proven in this initial study, DESs could decrease the total volume of chemical applied during the tanning process. The DESs are viscous and may be applied as a 'cream' to both sides of the hide similar to the 'roller-coating' process observed during the application of surface coatings to leather. Since both components of the DES are absorbed by the hide any liquid remaining can be physically squeezed from the hide and directly reused.

\section{Vegetable Tanning}

Chromium tanning is the technique used for the majority of leathers due to its relatively short tanning time, and high shrinkage temperature allowing the tanned leathers to be processed at higher temperature. Vegetable tanning agents form a smaller part of the market due primarily to the slow reaction kinetics and lower shrinkage temperatures. These tanning agents are potentially greener since the polyphenolic active ingredients are biodegradable and do not persist in the environment. In addition to the three chromium-based tanning DESs shown above, two organic vegetable tanning agents chestnut wood (Castanea sativa) and mimosa bark (Acacia meamsii) were used, each in a eutectic mixture of choline chloride and ethylene glycol (1: 2 molar ratio) at a loading of $10 \mathrm{wt} \%$. The hide samples were treated as described previously. Data are shown in Figure 2.

Vegetable tanning agents have poor solubility in water and are slow to solubilise. Figure $\mathbf{2 b}$ shows the mimosa extract tanning solution in Ethaline, and for comparison sake, the comparable aqueous system. It can clearly be seen that the extract is considerably more soluble in Ethaline producing a more transparent solution. Vegetable tanning agents are polyphenolic compounds which tend to be poorly dispersed in aqueous solutions. They are used extensively in the retanning process prior to dyeing and fatliquoring. In the DESs, vegetable tannins form intensely coloured homogeneous solutions and this evidently aids their dispersal into the collagen structure. It is unsurprising that the vegetable tanning agents dissolve readily in DESs, as these solvent systems are good hydrogen bond donators as well as organic and relatively polar. It is also evident from the cross sectional images in Figure 2a 
that the fibrous structure of the leather is retained during the tanning process in ionic liquids. Chestnut is a hydrolysable tanning agent which is based on saccharide compounds where the -OH groups are linked to tri-hydroxybenzene moieties through an ester linkage. The molecular weight affects the ability to bind and infuse in to the collagen structure. Mimosa is a condensed tanning agent which is similar to the hydrolysable tannins but is based on a flavonoid ring structure. More information about the complex structures of these tanning agents are provided in the literature. ${ }^{2}$ Condensed tanning agents generally have a higher tannin content but are more astringent. Hydrolysable tannins as their name suggests are more easily hydrolysed in acidic solutions to form products such as gallic acid. Condensed tannins, by contrast are less readily hydrolysed.

Despite the differences in the chemical composition, the tanned leathers have similar properties. The mimosa-tanned sample exhibited the highest tensile strength, while chestnut showed a large strain at break (Table 1). A typical vegetable tanning process for aqueous solutions may be several days. Although the samples shown in Figure 2 were undertaken for 18 hours for comparison sake with the samples shown in Figure 1, considerably shorter tanning periods may possibly be used. The shrinkage temperatures for the vegetable tanning agents listed in Table 1 are almost identical to those reported for the same process in water $\left(75-80^{\circ} \mathrm{C}\right)$ showing the applicability of this technique with the same efficacy. ${ }^{2}$

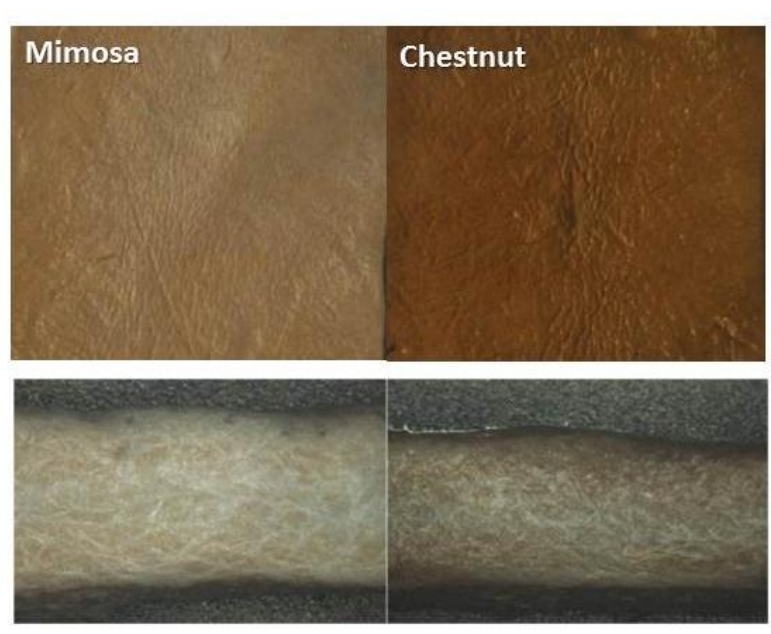

a

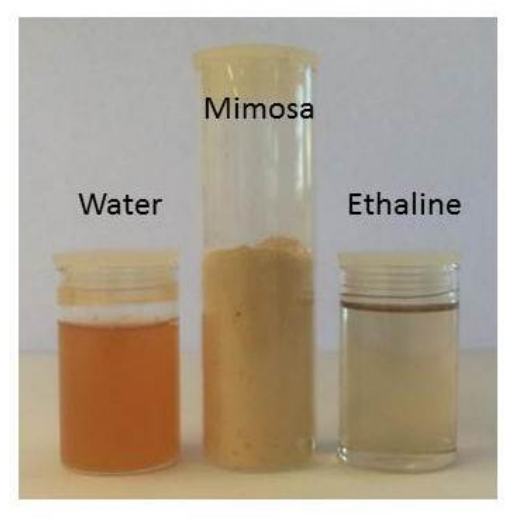

b

Figure 2: a) Above: From l to $r: 10 \times 10 \mathrm{~cm}$ samples of bovine hide, $\mathrm{pH}$ 4, tanned in mimosa in Ethaline, chestnut in Ethaline. Below: Corresponding cross sections. b) Mimosa tanning powder (middle) in water (left), and in Ethaline (right). 
A partial volume of the ethylene glycol: choline chloride-DES in the vegetable tanning liquid, is retained in the collagen structure following washing with water and drying. Both vegetable tanned samples increased their mass by $19 \%$ showing that the DES becomes trapped within the collagen structure. This may act as a lubricating phase imparting greater flexibility to the dried leather. Since the DES liquid exhibits very low volatility, it will be retained within the tanned leather. The lubricating behaviour may be seen from the greater strain at break values for the vegetable-tanned samples. It will be shown later that the trapped DES liquid may act as a lubricant that would normally be added during the post-tanning process. This is traditionally achieved using natural and synthetic fats and oils in a process known as "fatliquoring". ${ }^{2}$ A mass balance on the tanning process showed that the tanning liquid could be quantitatively recovered at the end of the process resulting in negligible waste. This is probably due to the low viscosity of these liquids compared with the chromium-based eutectics which tend to be a 100 times more viscous. Given that the liquid is not significantly depleted of tanning agent and so reused, this step of the tanning process has a Sheldon E factor of approximately zero.

It is noteworthy that the fibrous proteinaceous structure appears to remain unaffected, despite the high ionic strength. However, it should be noted that when the experiments were carried out using a bovine hide at $\mathrm{pH} 8$, the samples tanned with chromium and vegetable tannins, were translucent suggesting that the protein structure may have been compromised. This indicates that protonation of the collagen is likely to be important for the tanning agent to bind and stabilise the structure.

The mechanism by which species enter the collagen structure is contentious even from aqueous solutions. The $\mathrm{pH}$ of the hide $(\mathrm{pH} 4)$ suggests that osmotic swelling (diffusion of ions to neutralise charge imbalance) would be small in water. It is likely that the same is true for DESs whereas lyotropic swelling (absorbance of species which can disrupt the hydrogen bond structure) could be more significant. The high ionic strength could result in the DES acting as a deliquescent, resulting in a loss in mass which is not the case in most of the samples in Table 1 (and Figure 3), suggesting that lyotropic swelling is more important in the tanning process.

\section{Plasticising Leather}

Once the tanning step is complete, the leather is usually plasticised with an oil in a process known as fatliquoring. The oils used are mostly from plant or fish origins, and are poorly miscible with water and lead to turbid waste solutions which are difficult to treat. Previous 
experiments from vegetable tanning showed that the leather was flexible and soft and this is thought to originate from the DES trapped in the collagen structure. This may suggest that the DES acts as an in-built fatliquor. A sample of aqueous chromium-tanned bovine leather was soaked in Ethaline at various temperatures and periods of time. The amount of Ethaline absorbed is shown in Figure $\mathbf{3}$ as a function of time and temperature.
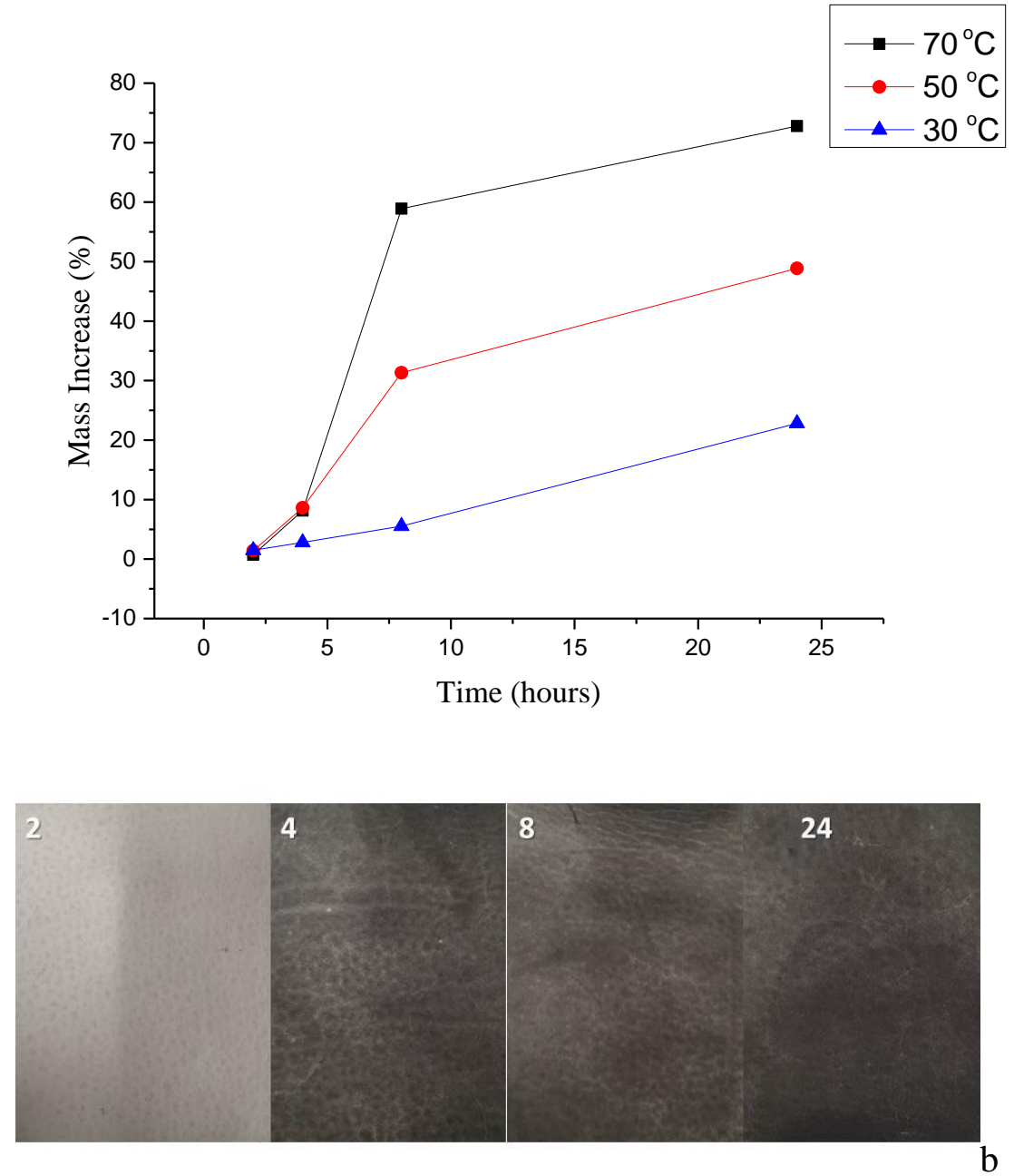

Figure 3: a) mass increase in leather soaking in Ethaline as a function of time and temperature, $b$ ) appearance of samples soaked in Ethaline at $70{ }^{\circ} \mathrm{C}$ for different times (hrs).

Following the soaking process, samples were washed in water and air dried. Interestingly the water content of the leather (determined by TGA) was lower than the untreated sample. A significant amount of DES could be absorbed into the leather e.g. at $70{ }^{\circ} \mathrm{C}$ for 24 hours the leather sample absorbed $73 \%$ by weight DES. It is evident from the appearance (Figure $3 \mathbf{b}$ ) that the structure of the leather can be changed by absorbing the DES. 

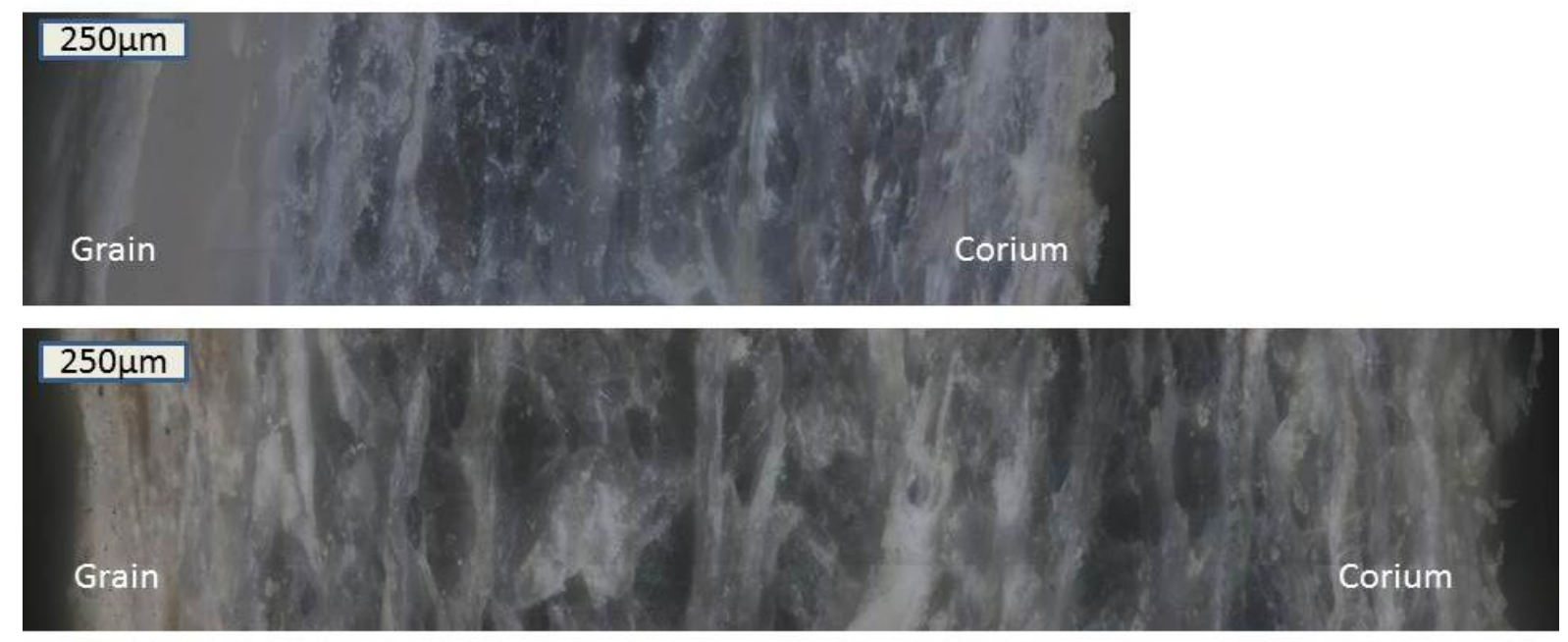

Figure 4: Cross-section of a standard aqueous chromium-tanned bovine leather before (above), and after (below) soaking in Ethaline at $70^{\circ} \mathrm{C}$ for $24 \mathrm{hrs}$. Images produced with an optical microscope.

Figure 4 shows the cross-sections of the leather before and after soaking in Ethaline. It is immediately apparent that the sample has swelled (56\%). The swelling also appears to be homogeneous across the cross-section, with no change in the grain structure of the material. Furthermore, the DES does not leach from the sample and will not drain when pressed with filter paper. It is therefore evident that the DES is bound to the collagen structure. This expansion of the collagen matrix appears to enable flexibility in the quaternary structure.

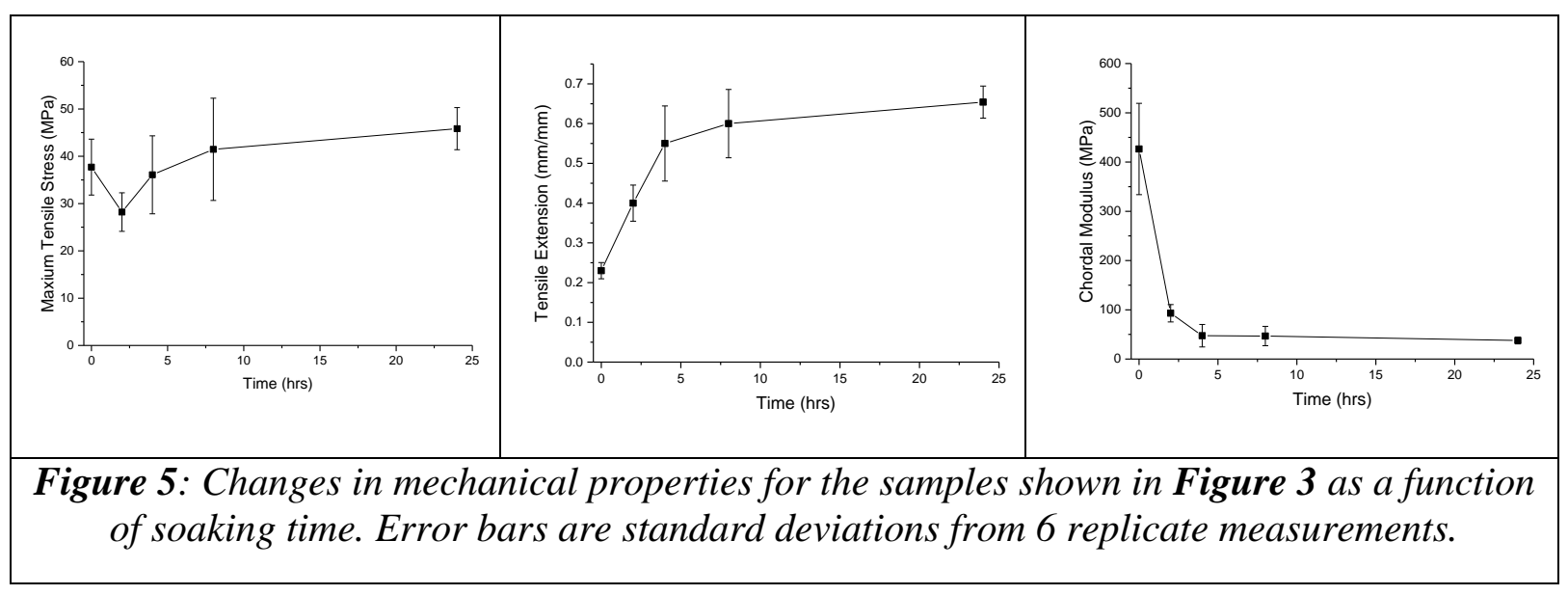

Figure 5 shows the mechanical properties of the chrome-tanned leather that has been soaked in Ethaline for different periods of time. It is clear that the tensile strength is approximately constant and the tensile strain doubles when soaked. One of the largest changes is in the flexibility of the material seen as the change in chordal modulus which decreases by 
approximately an order of magnitude when soaked for as little as 2 hours. While the results in Figures 3 and 4 show an extreme change in the properties of the leather the potential exists to tune the properties of collagen using ionic fluids.

The amount of DES absorbed increased with time and temperature as would be expected, however the water content of the hide remained at about $12 \%$, irrespective of the DES content compared to $18 \%$ in the untreated chromium tanned leather. This shows that the DES does not act as a hydrophilic additive as might be expected, instead the ability of the anion to hydrogen bond with the collagen structure will decrease its tendency to absorb moisture from the environment.

\section{Dyeing}

Acid dyes are currently the most prevalent dye type in the leather industry due to the miscibility with water, and fixed to collagen under acidic conditions. The colours available are wide ranging and exhibit good colour fastness. The molecules tend to be small and hydrophilic and generally anionic, binding electrostatically to protonated amino groups. The dyes also exhibit hydrogen bonding through auxochrome groups. Basic dyes are cationically charged and often more hydrophobic than the acid dyes with an affinity for anionic leather however, interaction also occurs via hydrogen bonding. Whilst they can produce vivid, bright colours they have poor colour fastness in comparison to acid dyes. A variety of dyes were solubilised in Ethaline including cationic dyes (Janus Black) and anionic dyes (Fast Black, Nuclear Fast Red and Polar Brilliant Red), however these dyes showed poor penetration into the leather and are readily leached out when washed with water. It should however be noted that in aqueous dyeing, charged dye adsorption is $\mathrm{pH}$-dependent and this is a parameter which will necessitate further investigation. A non-ionic, lysochromic dye Sudan Black B (Figure 6) was found to be soluble in DES and absorbed evenly throughout the leather. The dye produced an intense black shade which showed no evidence of leaching when the sample was washed in water. The dye penetrated throughout the cross-section of the leather (Figure 6) showing that the DES has transformed the collagen into a more hydrophobic environment. In principle absorbing the dye and DES into the tanned leather as a gel should remove all waste water treatment from the post tanning process. 


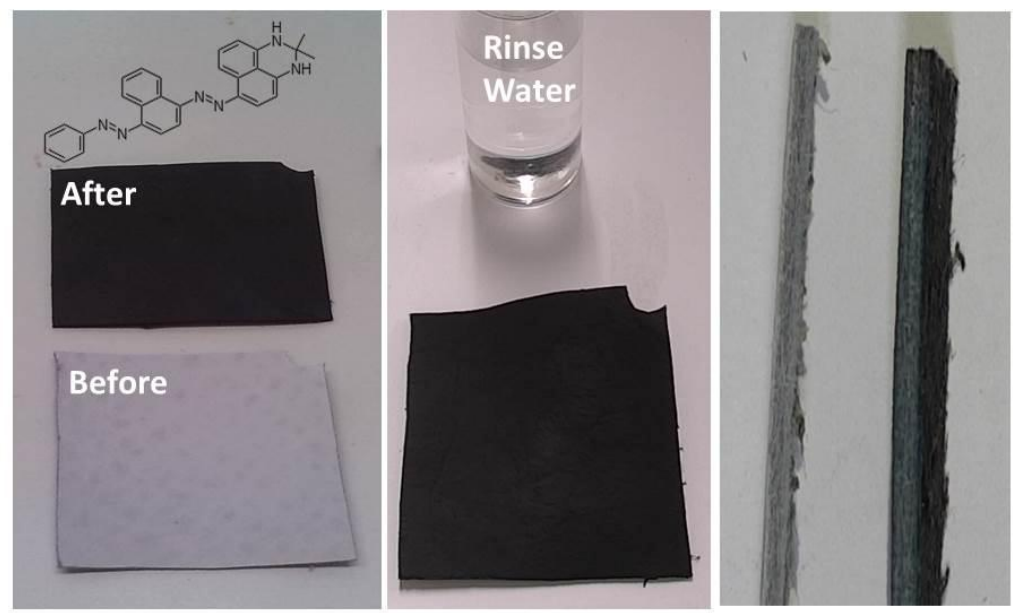

Figure 6: (Left) Standard aqueous chromium-tanned bovine leather before (below), and after (above) soaking in Ethaline containing 0.15 wt\% Sudan Black B at $70^{\circ} \mathrm{C}$ for 48 hours.

(Centre) water sample after washing leather for 15 minutes at $20^{\circ} \mathrm{C}$.

(Right) cross section of sample before and after dyeing.

\section{Conclusion}

This study has shown that deep eutectic solvent formulations may be used for tanning (using mineral and vegetable tannins) as well as dyeing and fatliquoring. The use of DESs could offer advantages in terms of waste minimisation by applying a liquid active-ingredient directly to the pelt surface. In principle, if the bulk or all of the DES is absorbed within the tanned material, there is the potential that there is negligible waste water. The current study (unoptimised) has shown comparable chromium uptake may be achieved however there is significant scope to improve the fixing of the chromium to the collagen to increase the shrinkage temperature of the tanned leather by optimising the binding of chromium to the collagen with different cross-linking anions. Vegetable tanning agents are shown to penetrate rapidly into the hide using DESs. This is possibly due to their ability to dissolve rather than disperse the active ingredients and their ability to open-up the hydrogen bond structure of collagen. DESs enable non-ionic dyes to be absorbed which do not bleed from the finished leather. Incorporation of the DES can also soften the leather considerably.

\section{Acknowledgements}

The financial support of the University of Tabuk is gratefully acknowledged for the studentship (OA) 


\section{References}

1 Kanagaraj, J. V. K,; Babu, N.; Sadulla, S. Solid wastes generated by the leather industry and its utilization for a cleaner environment - A review. J. Sci. Ind. Res. 2006, 65, 541-548.

2 Covington, A. D. Tanning Chemistry, the Science of Leather, RSC Publishing, Cambridge 2011.

3 Ozgunay, H.; Colak, S.; Mutlu, M.; Akyuz, F. Characterization of Leather Industry Wastes, Pol. J. Env. Stu. 2007, 16, 867-873.

4 Ros, M.; Ganter, A., Possibilities of reduction of loading of tannery waste, Water Sci. Tech. 1998, 37, 145-152.

5 Mwinyihija, M. Ecotoxicological Diagnosis in the Tanning Industry, Springer Science 2010.

6 Lofrano, G.; Meriç, S.; Emel Zengin, G.; Orhon, D. Chemical and biological treatment technologies for leather tannery chemicals and wastewaters: a review. Sci. Tot. Env. 2013, 461-462, 265-281.

7 Tünay, O.; Kabdaşli, I.; Arslan-Alaton, I.; Ölmez-Hanci, T. Chemical Oxidation: Application for Industrial Wasterwaters, IWA Publishing, London, 2010.

8 Kotaś, J.; Stasicka, Z. Chromium occurrence in the environment and methods of its speciation. Environ. Pollut. 2000, 107, 263-283.

9 Smith, E. L.; Abbott, A. P.; Ryder, K. S. Deep Eutectic Solvents (DESs) and their applications. Chem. Rev. 2014, 114, 11060-11082.

10 Abbott, A. P.; Boothby, D.; Capper, G.; Davies, D. L.; Rasheed R.; Tambyrajah V. Deep Eutectic Solvents Formed between Choline Chloride and Carboxylic Acids: Versatile Alternatives to Ionic Liquids. J. Am. Chem. Soc. 2004, 126, 9142-9147.

11 Abbott, A. P.; Barron, J. C.; Ryder, K. S.; Wilson, D. Eutectic-Based Ionic Liquids with Metal-Containing Anions and Cations. Chem. Eur. J. 2007, 13, 6495-6501.

12 Abbott, A. P.; Al-Barzinjy, A. A.; Abbott, P. D.; Frisch, G.; Harris, R. C.; Hartley, J. Ryder, K. S. Speciation, physical and electrolytic properties of eutectic mixtures based on $\mathrm{CrCl}_{3} \cdot 6 \mathrm{H}_{2} \mathrm{O}$ and urea. Phys. Chem. Chem. Phys., 2014, 16, 9047-9055.

13 Abbott, A. P.; Capper, G.; Davies, D. L.; Rasheed, R. Ionic Liquid Analogues Formed from Hydrated Metal Salts. Chem. Eur. J. 2004, 10, 3769-3774.

14 Jayakumar, G. C.; Mehta, A.; Rao, J. R.; Fathima, N. N. Ionic liquids: new age materials for eco-friendly leather processing. RSC Adv. 2015, 5, 31998-32005. 
15 Vijayaraghavan, R.; Vedaraman, N.; Muralidharan, C.; Mandald, A. B.;

MacFarlane, D. R. Green Chem. 2015, 17, 1001-1007.

16 Abbott, A. P.; Ryder, K. S.; König U. Electrofinishing of metals using eutectic based ionic liquids. Trans. Inst. Metal Fin. 2008, 86, 196-204.

17 Covington, A. D. Modern Tanning Chemistry Chem. Soc. Rev 1997, 26. 111-126

18 Stein, K.; Schwedt, G. Speciation of chromium in the waste water from a tannery. Fresen. J. Anal. Chem. 1994, 350, 38-43.

19 Raghava Rao, J.; Chandrasekaran, B.; Nair, B. U.; Ramasami, T.. Eco-benign management options for cleaner chrome tanning. J. Sci. Ind. Res. 2002, 61, 912-926. D. A. Boast, J. Am. Leather Chem. Assoc. 1988, 83, 17.

20 Tiravanti, G.; Petruzzelli, D.; Passino, R. Pretreatment of tannery wastewaters by an ion exchange process for Cr (III) removal and recovery. Water Sci. Technol. 1997, 36, 197-207.

21 Leyva, R. R.; Fuentes, R. L.; Guerrero, C. R.; Barron, M. M. J. Adsorption of trivalent chromium from aqueous solutions onto activated carbon. J. Chem. Technol. Biotechnol. 1995, 62, 64-67.

22 Suresh, V.; Kanthimathi, M.; Thanikaivelan, P.; Rao, J. R.; Nair, B. U. An improved product-process for cleaner chrome tanning in leather processing. J. Clean. Prod. 2001, 9, 483-491. 
For Table of Contents Use Only.

\section{Processing of Leather Using Deep Eutectic Solvents}

Andrew P. Abbott, ${ }^{\text {a }}$ Omaymah Alaysuy, ${ }^{a}$ A. Paula M. Antunes, ${ }^{b}$ Andrew C. Douglas, ${ }^{a}$ Jeffry Guthrie-Strachan, ${ }^{\mathrm{b}, \mathrm{c}}$ William R. Wise ${ }^{\mathrm{b}}$

${ }^{\mathrm{a} C h e m i s t r y ~ D e p a r t m e n t, ~ U n i v e r s i t y ~ o f ~ L e i c e s t e r, ~ L e i c e s t e r, ~ L E 1 ~ 7 R H, ~ U K ~}$

${ }^{\mathrm{b}}$ Institute for Creative Leather Technologies, University of Northampton, Northampton, NN2 7AL, UK

${ }^{\mathrm{c}}$ Trumpler GmbH \& Co. KG, Worms, 67547, Germany

\section{Graphical Abstract}

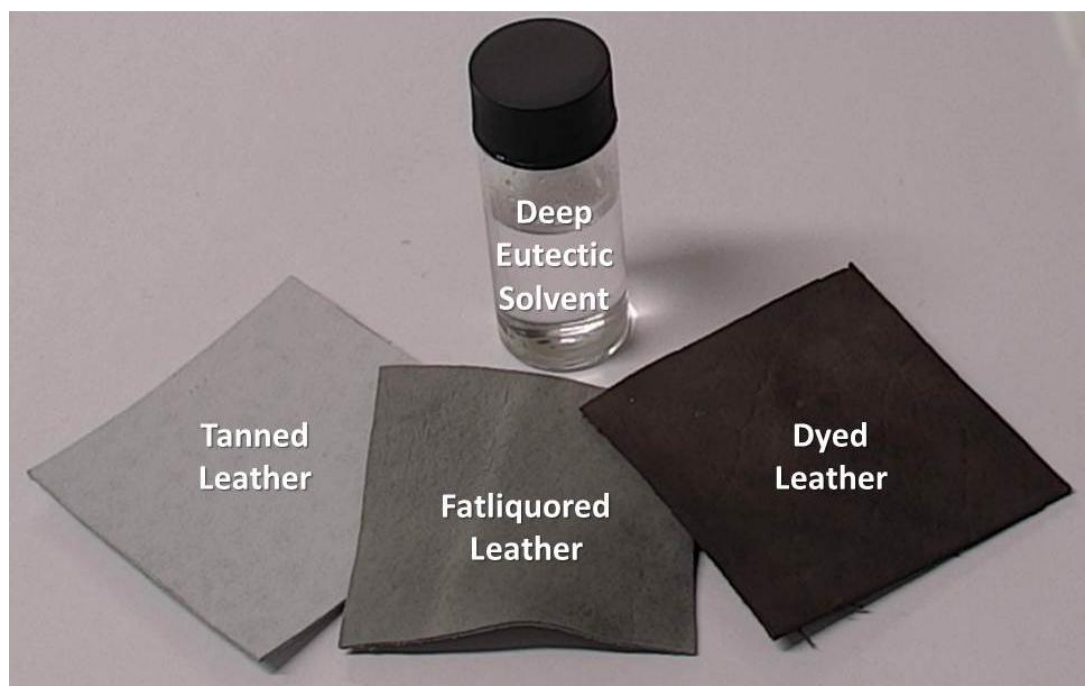

Tanning and dyeing of leather has historically been associated with large volumes of aqueous waste but this paper shows how Deep Eutectic Solvents can be used to minimise waste in the a variety of leather processing steps. 